\title{
Tagmemics Analysis of Using Language Linguistic Data of Banyuwangi
}

\author{
Ika Febriani \\ Universitas Trunojoyo Madura \\ Bangkalan, Indonesia
}

\begin{abstract}
This research were intended to analyze the linguistic data of Using language in Banyuwangi by using Tagmemics analysis. Language analyzes in Indonesia mostly use structural theory. In keeping with the development of the times in reality the structural analysis of language cannot fully apply in the investigation of the subtleties of language in the field. Hence the need for other theories capable of analyzing in relation to the investigation of language subtleties is more intensive than structural analysis. Based on the above facts, language researchers in Indonesia have a great interest in the application of Tagmemics theory in the investigation of the subtleties of language in Indonesia. This research used qualitative approach research procedure and the data analysis tekhnique is based on Pike theory of tagmemics. Evidenced by the emergence of language investigation in Indonesia by using Tagmemics theory among them Using Language in Banyuwangi. The data of this research are linguistic data that consists of the clauses in Banyuwangi society with Using Language. Tagmem as the unit of language which is the basis of Tagmemics analysis is also explained by giving characteristic filler function of $S, P, O$, and so on. In the Using language constructs predicate function predates the subject. The construction of intransitive clauses in using languages coexists directly with the complementary, locative, and range-filled complement slots function. Proven eclectic nature in analyzing with Tagmemics theory of linguistics.
\end{abstract}

Keywords-tagmemics, using language, linguistic data

\section{INTRODUCTION}

Using language as a recognized regional language has existence is a language with a unique structure. This uniqueness causes many analyzes done on the language one of them based on Tagmemics theory.

As the times progressed, in order to use the language to use the extinct need to be preserved by analyzing the language. Analyzing using Tagmemics language has been done by Dendy Sugono on transitive verb form. For that, it needs to be analyzed with Tagmemics theory on using clause structure.

Tagmemic theory is concerned primarily with grammatical analysis and is especially associated with Kenneth Lee Pike. It is an offshoot of structuralism. Walter A Cook, S.J [1] with his book entitled Introduction to Tegmemic Analysis the tagmemics flow (in the sense of a complete tagmemic flow) was pioneered by Kenneth L. Pike, a figure from the summer institute of linguistic, who bequeathed Bloomfield's views so that this flow was structuralism. Structuralism ignored functions of a linguistic form and concentrated only on form. The analysis in Tagmemics theory describes language based on tagmem that combines traditional concepts with word class (categories) such us noun $(\mathrm{N})$, verb $(\mathrm{V})$, adjective, adverb (Adv). Tagmemics Theory analyzes an element or unit in sequence and sequence (sequential and aquipollent), which is called string analysis. From the view in Tagmemics theory can be said that by mastering tagmemics theory will be easier to learn other theories [2]. It is related to one of Pike's opinion other contributions to linguistic theory is his distinction between emic and etic viewpoints [3].

Characteristics of Tagmemics flow analysis of function or sentence positions on Traditional theory is selected and placed on the slot dimension [4]. In Tagmemics theory there are grammatical units called tagmem. Tagmem-tagmem consists of interchangeable functional slots and complement each other or occupy the slot. To analyze or describe language with Tagmemics theory, tagmem is the most important basic unit of syntagmatic analysis. The main unit of tagmemics analysis is the tagmem that deals with functional slots and categories that fill the slot.

\section{A. Tagmem}

The unity in Tagmemics analysis is tagmem, correlation of a functional lane with classes of grains that fill the lane. Furthermore, according to Tarigan this unity is not merely the unity of forms as contained in other grammatical models but a combination of functions and forms [5]. Robin said that tagmem is a container in a structure (syntactic or morphological) along with the formal class of elements that occupy the container (often associated with that contained in the literature as the 'path' and 'filler').

Pike provides four characteristics of tagmem: structural gates (slots), substitution classes, roles, and cohesion (framework and control) [6]. The unit of a construction described in these four traits is called tagmem. Pike further explained the contrast between gatra, class, role, and cohesion can also be related to the terms: (1) syntagmatic relationships with a whole larger set of inner parts, (2) paradigmatic classes of corresponding parts and can be replaced by the same place; the pragmatic relevance of the cut type behavioral function, (4) the suitability of the elements.

Tagmem as the unit of language which is the basis of Tagmemics analysis is also explained by giving characteristic filler function of subject, predicate, object, and so on. Tagmem unifies traditional concepts such as subject, predicate, object, 
complement, locative, temporal, recipient, actor, with the concept of noun class, verb, pronouns, adjectives, adverbs, etc.

\section{B. Types of Tagmem Presence in Construstion}

According to Tarigan tagmem is a correlation of forms distributed in the construction of language with the possibility of the type of existence that is mandatory or may choose against construction, core or area of construction, and distributed in a fixed position or free movement [5]

Tagmem is required to be marked with a plus sign (+) that it must be present. Tagmem may be marked with a plus-minus sign ( \pm ) that the tagmem may / may occur. A core tagmem may be mandatory or may be selectable. Broad tagmem is always optional [5].

\section{METHODS}

Qualitative approach is used in this research. The kind of qualitative approach is language research. This research used research procedure and the data analysis technique is based on Pike theory of tagmemics. Evidenced by the emergence of language investigation in Indonesia by using Tagmemics theory among them Using Language in Banyuwangi. The data of this research are linguistic data that consists of the clauses in Banyuwangi society with Using Language.

The method of language research used in this research is the method of agih with basic technique [7]. Sudaryanto [7] said so called because the way used at the beginning of the analytical work is to divide the lingual unit of data into several parts or elements and the elements concerned are viewed as a direct part to form the lingual unit in question.

\section{RESEARCH RESULT}

The Tagmemics model consists of a series of syntactic statements at sentence levels, clauses, phrases, and words [5]. Furthermore, Tarigan stated in the analysis of a sentence, those elements which can be removed from the structure are marked as "optionable" (optional) and others are required.

\begin{tabular}{c|l} 
Slot & Class \\
\hline Role & Cohession
\end{tabular}

\section{A. Tagmemics Analysis the Linguistic Data of Using} Language

Analyzing with Tagmemics theory uses formulas with abbreviations of terms. The following are the sentences discussed in this paper.

(1) mari lakine matay, mung emake mbandhani lare $i k a u$ 'after her husband died, only her mother took the child'

(2) dulure hang cilik ikai hing bisa megyawek ring papan liya'this little brother can not work anywhere else'

(3) emake ikau nangis ring umyah 'her mother was crying at home'
(4) bengen hing bener emak ring sawah'old unnatural mother in the fields'

(5) yene longgoh ring papane dhyewek' he sits in his place'

1. Mari lakine matay, mung emake mbandhani lare ikau

In the data (1) there are two clause constructs, such us:

(1a) mari lakine matay

(1b) mung emake mbandhani lare ikau

If the clause construction (1a) is concerned, the tagmem can be found as follows.

(1a) mari lakine matay Conj. S:N P: Vin

(1a) $\mathrm{Cla}= \pm$ conn:konj $+\mathrm{S}: \mathrm{NP}+\mathrm{P}: \mathrm{VP}$

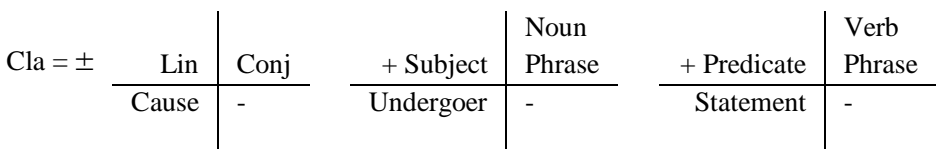

The construction of the clause consists of a connecting fill tag or a connector filled by the conjunction class, the slot filler tag $\mathrm{S}$ filled by class $\mathrm{N}$, and followed by the sl tag of the function slot filled by the class nucleus verb. Similar to the construction of clause (1b), if we note that tagmem-tagmem filler slot function is as follows.

\begin{tabular}{|c|c|c|c|c|c|c|}
\hline (1b) $\underline{\mathrm{m}}$ & ng ema & & mbandhani & & & \\
\hline & Actor:N & & $P: V$ & & Indergoer & \\
\hline (1b) & $=+\mathrm{S}: \mathrm{N}$ & & $+\mathrm{P}: \mathrm{V}$ & & indergoer & NP \\
\hline $\mathrm{Cla}=+$ & Subject & NP 1 & $+\mathrm{P}$ & VP & + Object & NP 2 \\
\hline & Actor & - & Sta & - & Undergoer & - \\
\hline
\end{tabular}

The clause construct consists of a slot filler fill tagmem filled by $\mathrm{N}$ class followed by the sl tag of the function slot $\mathrm{P}$ that is filled by class Vt and followed by the Pendent tagmem filled by class N. Construction clause (1a) can not stand alone into a major sentence but must be embedded in the clause (1b) so that it is inserted into the clause group bound. The clause attachment (1a) is caused by the tagmem of the connector or connector slot filled by the $\{$ mari $\}$ 'conjunction of' which is located in the left-hand position. The clause construction (1b) has the ability to be a major sentence so that it is inserted into a group of free clauses.

Hierarchically, the construction of $\{$ mari lakine matay outer slot filler (margin), construction \{emake mbandhani lare ikau core slot charger (nucleus), construction \{after / mari\} connector or connector slot, \{matay\} slot charger P, phrase construction \{lakine\} slot charger $\mathrm{S}$, construction \{mung emake slot function $\mathrm{S}$, construction \{mbandhani\} function slot filler $\mathrm{P}$, and construction \{anake\} filler slot function $\mathrm{O}$ undergoer.

Formula subordinates sentence (1) as follows. Mari Lakine

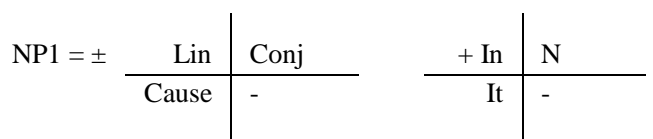


The above formula reads the noun phrase consisting of the outer core tagmem is optional with the connector role filled with the conjunction and the core tagmem is mandatory with the role of the item filled with the noun.

$$
\begin{aligned}
& \text { laki + -ne }
\end{aligned}
$$

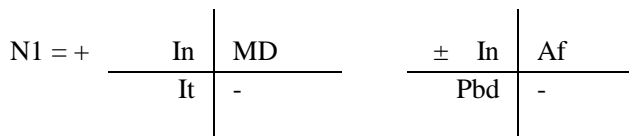

The above formula is read: the noun consists of a mandatory core tagmem with the role of the item filled in the base / origin morpheme and the outer tagmem of the core is optional with the forming role of the affixed object with the ne-suffix shape.

$$
\begin{aligned}
& \text { matay } \\
& \mathrm{VP} 1=+\quad \begin{array}{l|l}
\text { In } & \mathrm{V} \\
\hline \text { It } & -
\end{array}
\end{aligned}
$$

The above formula is read: a verb phrase composed of mandatory core tagmem with the role of an item filled with verbs.

$$
\begin{aligned}
& \text { mung emake }
\end{aligned}
$$

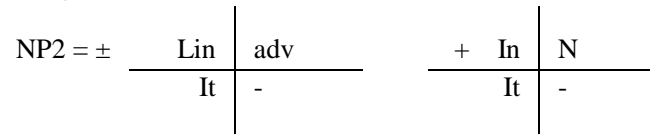

The above formula is read: the noun phrase comprising the outer core tagmem is optional with the role of the item filled by the adverb and the mandatory core tagmem with the item role of the noun filled.

$$
\begin{aligned}
& e m a k+-e
\end{aligned}
$$

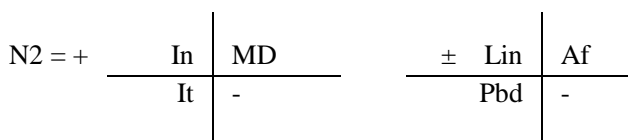

The above formula is read: the noun consists of a mandatory core tagmem with the role of the item filled with the base / origin morpheme and the outer core tagmem is optional with the forming role of the affixed object with the form of the -e suffix.

$$
\begin{array}{l|l}
\text { mbandhani } \\
\mathrm{VP} 2=+ \\
\hline \text { In } & \mathrm{V} \\
\hline \text { It } & -
\end{array}
$$

The above formula is read: the verb phrase composed of the core tagmem is optional with the role of the item filled by the verb.

$$
\begin{aligned}
& m-i+\text { bandhani or } m-+ \text { bandhani }+-i
\end{aligned}
$$

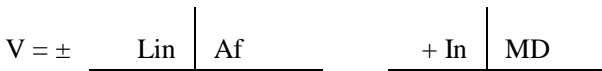

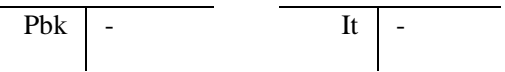

The above formula is read: a verb comprising an outer core tagmem is optional with a work-forming role filled with the affix of the m-i conf config form and the mandatory core tagmem with the role of the item filled with the basic / origin maorfem.

$$
\begin{aligned}
& \text { lare ikau }
\end{aligned}
$$

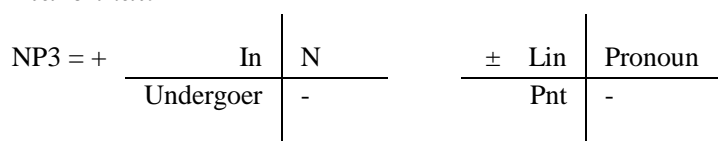

The above formula is read: the noun phrase composed of mandatory core tagmem with the patient's role filled by the noun followed by the outer core tagmem is optional with the decisive role filled by the pronoun point

\section{Dulure hang cilik ikai hing bisa megyawek ring papan liya}

The clause construction (2) follows the S-P sequence pattern that is capable of constructing at least a major sentence. Tagmem filler slot function $\mathrm{S}$ and $\mathrm{P}$ contains mandatory properties. The clause construction in addition to containing the slot tag slot S-P also contains the tagmem-filler function O. Syntactically in behavior in larger units expanded by presenting tagmem filler slot $\mathrm{Aj}$. The clause construction (2) contains the $\mathrm{Aj}$ function fill slot occupying a certain position.

Dulure hang cilik ikai bisa megyawek ring papan liya

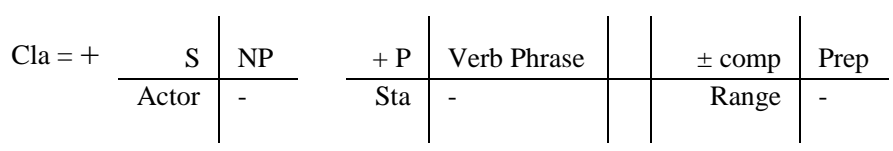

The clause consists of a mandatory subject tagmem with the role of the actor filled with the noun phrase, the predicate tagmem is mandatory with the role of the statement filled with the verb phrase, and the complement tagmem is optional with the range role filled with the preposition phrase.

Here's the subordinate formula clause below.

Dulure hang cilik ikai

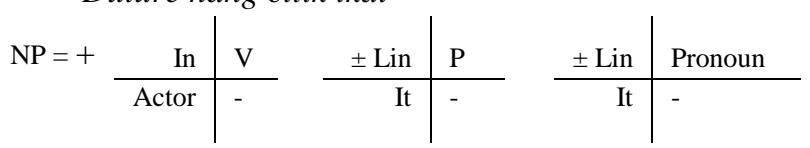

The above noun phrase construction consists of mandatory core tagmem with the role of the actor filled with verbs, the outer core tagmem is optional with the role of the item filled by the particle, the outer core tagmem is optional with the role of the item filled by the adjective, and the tagmem outside of the core is optional with the role of the item filled by the pronoun point.

$$
\begin{aligned}
& \text { Dulur + -e }
\end{aligned}
$$

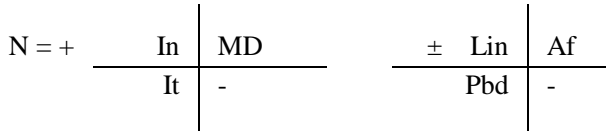


The above formula is read: the noun consists of a mandatory core tagmem with the role of the item filled with the base / origin morpheme and the outer core tagmem is optional with the forming role of the affixed object with the form of the suffix -e.

Hing bisa megyawek

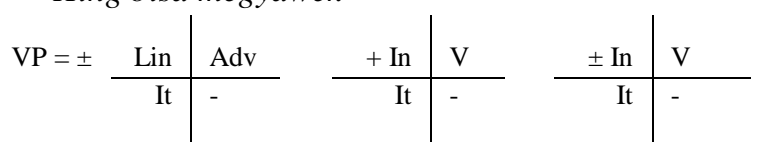

The construction of the above verb phrase comprising the outer core tagmem is optional with the role of the item filled by the adverb, the mandatory core tagmem with the role of the item filled by the verb, the core tagmem is mandatory with the role of the item filled by the verb.

$$
\begin{aligned}
& \text { me- + gyawek }
\end{aligned}
$$

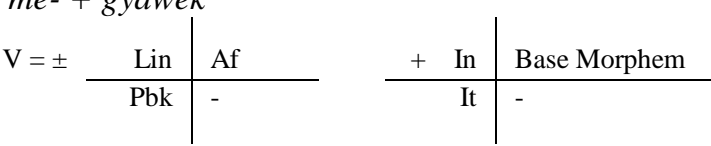

The above formula is read: the verbs comprising the outer core tagmem are optional with a working-forming role that is affixed to the prefix form and the mandatory core tagmem with the role of the item filled with the base / origin morpheme.

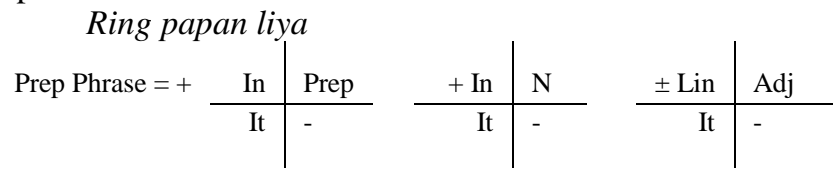

The construction of the preposition phrase consists of a mandatory core tagmem with the role of an item filled with the preposition, the core tagmem is mandatory with the role of the item filled in the noun, and the outer core tagmem is optional with the role of the item filled with the adjective.

\section{Emake ikau nangis ring umyah}

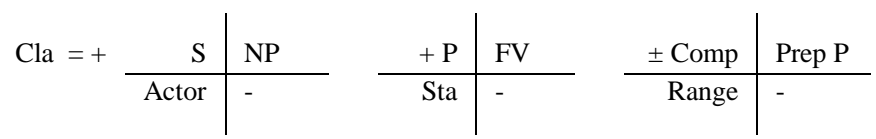

The above clause construction consists of a mandatory subject tagmem with the role of the actor filled with the noun phrase, the predicate tagmem is mandatory with the role of a statement filled with the verb phrase, and an optional complement tagmem with a range role filled with the preposition phrase.

The following subordinate clause construction formula is as follows.

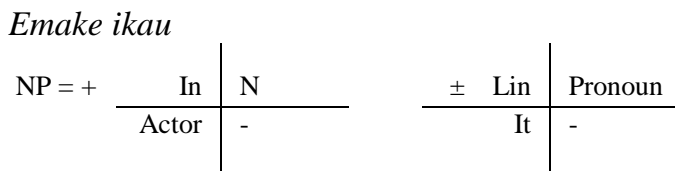

The above formula consists of mandatory core tagmem with the role of the charged actor noun and the outer core tagmem is optional with the role of the item filled with the pronoun of the pointer.

$$
\begin{aligned}
& \text { Nangis } \\
& \mathrm{VP}=+\quad \begin{array}{l|l}
\text { In } & \mathrm{V} \\
\hline \text { It } & -
\end{array}
\end{aligned}
$$

The above formula is read: the verb phrase comprising the mandatory core tagmem with the role of the item filled by the verb.

$$
\begin{aligned}
& \text { n- +tangis }
\end{aligned}
$$

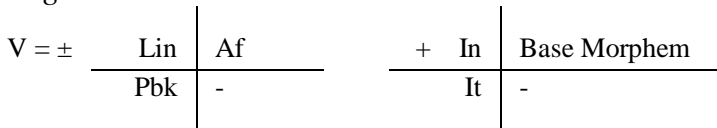

The above formula is read: a verb comprising an outer core tagmem is optional with a work-forming role filled with the prefix of the prefix $n$ - and the mandatory core tagmem with the role of the item filled with the base / origin morpheme.

Ring umyah

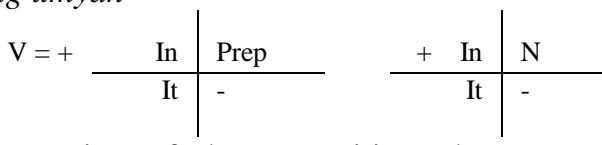

The construction of the preposition phrase consists of mandatory core tagmem with the role of an item filled with the preposition and the core tagmem being mandatory with the role of the item filled with the noun.

\section{Bengen hing bener emak ring sawah}

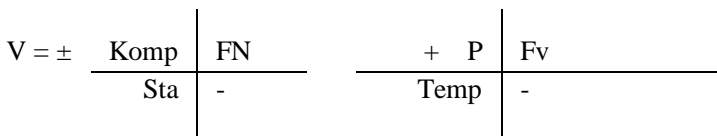

$$
\begin{aligned}
& \begin{array}{r|lr|l}
\mathrm{S} & \mathrm{FN} \\
\hline \text { Actor } & - & \pm \text { Komp } & \text { Prep P } \\
\hline \text { Loc } & -
\end{array}
\end{aligned}
$$

The above clause construction consists of the tagmem \{bengen\} as complement is optional with the temporal role, tagmem \{hing bener $\}$ as mandatory predicate with the role of statement, tagmem $\{\mathrm{emak}\}$ as the subject is mandatory to contain the role of the actor or the experiment, and the tagmem \{ring sawah filler as complement contains a locative role.

The subordinate clause formulas are as follows.

$$
\begin{aligned}
& \text { Bengen }
\end{aligned}
$$

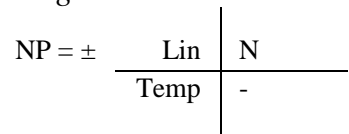

The above formula is read: the noun phrase consists of an optional tagmem with a temporal role filled with nouns.

\section{Hing bener}

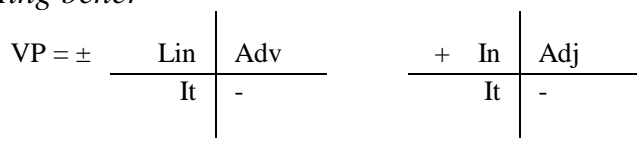

The construction of the above verb phrase comprising the outer core tagmem is optional with the role of the item filled by the adverb and the mandatory core tagmem with the role of the item filled by the adjective. 


$$
\begin{aligned}
& \text { Ring umyah }
\end{aligned}
$$

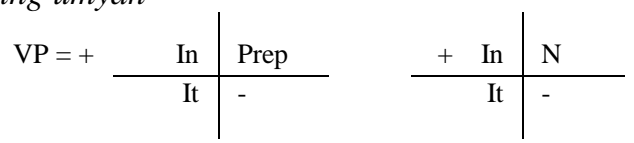

The construction of the preposition phrase consists of mandatory core tagmem with the role of an item filled with the preposition and the core tagmem being mandatory with the role of the item filled with the noun.

\section{Yene longgoh ring papane dhyewek}

$$
\mathrm{Cla}=+\begin{array}{r|lr|l}
\mathrm{S} & \mathrm{NP} \\
\hline \text { Actor } & - & +\mathrm{P} & \mathrm{VP} \\
& - & \pm \text { Comp } & \text { Prep P } \\
\hline \text { Range } & -
\end{array}
$$

The above clause construction consists of a mandatory subject tagmem with the role of the actor filled with the noun phrase, the predicate tagmem is mandatory with the role of a statement filled with the verb phrase, and an optional complement tagmem with a range role filled with the preposition phrase.

The following subordinate clause construction formula is as follows.

$$
\begin{array}{l|l}
\text { Yene } \\
\mathrm{NP}=+ \\
\hline \text { Actor } & -
\end{array}
$$

The above formula consists of the mandatory core tagmem with the actor role filled with nouns.

$$
\begin{aligned}
& \text { Longgoh } \\
& \mathrm{VP}=+\begin{array}{l|l}
\text { In } & \mathrm{V} \\
\hline \text { It } & -
\end{array}
\end{aligned}
$$

The above formula is read: the verb phrase comprising the mandatory core tagmem with the role of the item filled by the verb.

$$
\begin{aligned}
& \text { Ring papane dhyewek } \\
& \text { Prep } \mathrm{P}=+\begin{array}{r|l|l|l|l}
\text { In } & \text { Prep } \\
\hline \text { It } & - & + \text { In } & \mathrm{N} \\
\hline \text { It } & - & \pm \text { Lin } & \text { Adv } \\
\hline \text { It } & -
\end{array}
\end{aligned}
$$

The construction of the preposition phrase consists of mandatory core tagmem with the role of an item filled with the preposition, the core tagmem is mandatory with the role of the item filled in the noun, and the outer core tagmem is optional with the role of an item filled with the adverb.

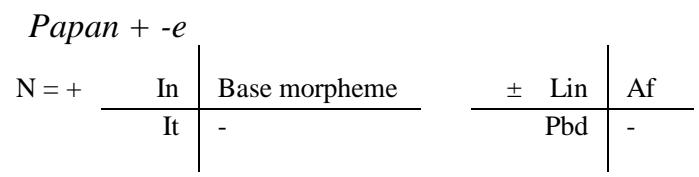

The above formula is read: the noun consists of a mandatory core tagmem with the role of the item filled with the base / origin morpheme and the outer core tagmem is optional with the forming role of the affixed object with the form of the suffix -e.

- Intransitive clause

(2) dulure hang cilik ikai hing bisa megyawek ring papan liya
(3) emake ikau nangis ring umyah
(4) bengen hing bener emak ring sawah
(5) yene longgoh ring papane dhyewek

The above clause construction includes an intransitive clause marked with 'megyawek', 'nangis', 'hing bener' verbs, and 'longgoh' $\mathrm{P}$ slot chargers which do not require the presence of a slot of a patient object. Expansion possibilities are only side by side directly with complement slots that indicate temporal, locative, or range.

\section{CONCLUSION}

In the using language clause construction includes an intransitive clause marked with 'megyawek', 'nangis', 'hing bener' verbs, and 'longgoh'. The clauses constructs predicate function predates the subject. The construction of intransitive clauses in Using languages coexists directly with the complementary, locative, and range-filled complement function slots. Proven eclectic nature in analyzing with Tagmemics theory of linguistic data Using language Banyuwangi. Such uniqueness is particularly in the step and form of analyzing linguistic data. The clauses with consists of the function of slot in using language is diversed. We hope that all this research can be develop step of research about using language of Banyuwangi.

\section{REFERENCES}

[1] W. A. Cook, Introduction to Tagmemic Analysis. New York : Georgetwon University. 1978.

[2] P. J. Sitorus,. Struktur Sintaktis Bahasa Batak Toba: Analisis Tagmemik dan Analisis Konstruksi Tema-Rema. Thesis. Universitas Negeri Surabaya: unpublished, 2002.

[3] A. Muqit, "Tagmemics: An Introduction to Tagmemics Concepts," Jurnal Bahasa dan Sastra, vol. 1, pp. 1-8, 2012.

[4] Soeparno. Aliran Tagmemik: Teori, Analisis, dan Penerapan dalam Pembelajaran Bahasa. Yogyakarta: Tiara Wacana. 2008.

[5] H. G. Tarigan, Pengajaran Tata Bahasa Tagmemik. Bandung: Angkasa. 1989.

[6] K.L.Pike, Konsep Linguistik Pengantar Teori Tagmemik. Jakarta: Summer Institute of Linguistics. 1992.

[7] Sudaryanto, Metode dan Teknik Analisis Bahasa: Pengantar Penelitian Wahana Kebudayaan secara Linguistis. Yogyakarta: Sanata Dharma University Press. 2018. 